\title{
Perfil de estudantes da Escola de Enfermagem da Universidade de São Paulo (1980-81)*
}

\author{
Profile of alumni of the University of São Paulo School of Nursing (1980-81) \\ Perfil de estudiantes de la Escuela de Enfermería de la Universidad de São Paulo (1980-81) \\ Natália Fialho Mota ${ }^{1}$, Amanda Loos Agra ${ }^{1}$, Juliana Moreira Lino Viana ${ }^{1}$,
Magali Hiromi Takashi ${ }^{1}$, Taka Oguisso ${ }^{2}$, Genival Fernandes de Freitas
}

\section{RESUMO}

Objetivos: Identificar os egressos da Escola de Enfermagem da Universidade de São Paulo no período delineado e contribuir para a recuperação da memória da EEUSP e sua inserção no conjunto das escolas de enfermagem consideradas pioneiras no Brasil. Métodos: Utilizou-se instrumento para a coleta dos dados sócio demográficos do universo pesquisado. Resultados: Foram estudados 163 ex-alunos, sendo que 23,9\% formaram-se em 1980 e 76,1\%, em 1981. O perfil dessa população é, predominantemente, feminino, procedente de São Paulo e de cor branca. Conclusão: O estudo propiciou a continuidade do trabalho pioneiro iniciado na década de 1970, na referida Escola, no qual foram identificados os alunos formados no período de 1946 - 1979, contribuindo para o resgate histórico da memória da enfermagem.

Descritores: Escolas de Enfermagem/historia; Estudantes de Enfermagem/história; Educação em Enfermagem.

\begin{abstract}
Objectives: To identify and describe the characteristics of the alumni of University of São Paulo School of Nursing from 1980 to 1981 and to contribute to the retrieval of the memory and insertion of this institution in the group of pioneer Brazilian schools of nursing. Methods: A sociodemographic questionnaire was used to collect data among 163 alumni. Results: Approximately one fourth of the alumni $(23.9 \%)$ graduated in 1980 and $76.1 \%$ graduated in 1981. The alumni consisted of white females from São Paulo. Conclusions: The study contributed to the continuity of pioneer work initiated in the decade of 1970 at the University of São Paulo School of Nursing, in which researchers identified and characterized alumni who graduated from 1946 to 1979. The study's findings contribute to the retrieval of history of memory of nursing.
\end{abstract}

Key Words: Schools of Nursing; History; Nursing Alumni; Nursing Education.

\section{RESUMEN}

Objetivos: Identificar los egresados de la Escuela de Enfermería de la Universidad de Sao Paulo en el período de 1.980 a 1981 ; y, contribuir para la recuperación de la memoria de esa Institución y su inserción en el conjunto de las escuelas de enfermería consideradas pioneras en Brasil. Métodos: Se utilizó un instrumento para la recolección de los datos sociodemográficos del universo investigado. Resultados: Fueron estudiados 163 ex-alumnos, siendo que 23,9\% se graduaron en 1980 y 76,1\%, en 1981. El perfil de esa población es, predominantemente, femenino, procedente de Sao Paulo y de color blanco. Conclusión: El estudio propició la continuidad del trabajo pionero iniciado en la década de 1970, en la referida Escuela, en el cual fueron identificados los alumnos formados en el período de 1946 a 1979, contribuyendo para el rescate histórico de la memoria de la enfermería.

Palabras clave: Escuelas de Enfermería/historia; Estudiantes de Enfermería/historia; Educación en Enfermería.

\footnotetext{
*Trabalho realizado na Escola de Enfermagem da Universidade de São Paulo. São Paulo (SP), Brasil. Trabalho financiado pela Fundação de Amparo à Pesquisa do Estado de São Paulo (FAPESP). Os resutlados apresentados fazem parte de um projeto maior que receben apoio dessa Instituição.

1 Acadêmicas do Curso de Enfermagem da Escola de Enfermagem da Universidade de São Paulo. São Paulo (SP), Brasil.

${ }^{2}$ Doutora em Enfermagem. Advogada. Professora Titular do Departamento de Orientação Profissional da Escola de Enfermagem da Universidade de São Paulo. São Paulo (SP), Brasil.

${ }^{3}$ Doutor em Enfermagem. Advogado. Professor do Departamento de Orientação Profissional da Escola de Enfermagem da Universidade de São Paulo. São Paulo (SP), Brasil.
} 


\section{INTRODUÇÃO}

Estudos têm ressaltado a importância do acervo histórico para a memória da enfermagem, o que contribui para a consciência política e a formação dos futuros enfermeiros. Por exemplo, sabe-se que o Arquivo Histórico da Escola de Enfermagem Anna Nery da Universidade Federal do Rio de Janeiro (EEAN-UFRJ) - seu atual Centro de Documentação (CD), formou-se de maneira espontânea, em razão das atividades administrativas e pedagógicas da Instituição. Hoje, o Arquivo detém um rico e significativo patrimônio em documentos preservados. Esses documentos são cartas, relatórios, comunicações, históricos acadêmicos, livros de atas, fotografias e outros registros, que pertencem à história da Escola, desde sua criação até os dias atuais ${ }^{(1)}$.

Ao discorrer sobre a organização do CD da EEAN/UFRJ, observa-se o valor da preservação documental e dos registros históricos ${ }^{(2)}$. Nessa perspectiva, percebe-se a importância dos documentos históricos, imagens e registros, os quais podem ajudar na recuperação da memória de uma instituição, profissão ou povo, considerando-se o fato de que os documentos servem como fontes de informações para profissionais de diversas áreas do conhecimento. Daí a importância acerca do valor dos documentos para a formação de uma consciência social sobre a significação e a utilidade de acervos documentais e a imperiosa necessidade de sua preservação e disponibilização para o público, em geral.

Em 2005, vários discentes interessaram-se em participar da confecção de subprojetos articulados ao projeto temático intitulado "O desenvolvimento histórico social da profissão de Enfermagem" ligado ao Grupo de Pesquisa História e Legislação da Enfermagem da Escola de Enfermagem da Universidade de São Paulo. Como resultado, o projeto proposto, pretendeu realizar um levantamento de ex-alunos formados no período de 1980 a 1981, compondo, assim, uma galeria. A escolha do tema e período estudados justificam-se pelo fato de, no final dos anos 1970, Amália Corrêa de Carvalho ter dado início ao levantamento dos egressos dessa Escola da primeira turma de 1946 até o ano de $1979^{(3)}$.

A Escola de Enfermagem da Universidade de São Paulo (EEUSP), criada pelo Decreto-Lei n ${ }^{\circ} 13.040$, de 31 de outubro de 1942, prepara enfermeiros, docentes, pesquisadores e especialistas em todos os ramos da Enfermagem, promovendo a realização de estudo, pesquisas e cursos para o aperfeiçoamento do ensino e do exercício da Enfermagem e da Obstetrícia. Presta serviços à comunidade em cooperação com os poderes públicos e entidades particulares, visando a melhoria das condições de saúde da população e o desenvolvimento da Enfermagem nos âmbitos local, nacional e internacional.

Cabe pontuar que a década de 1960 caracterizou-se pelo golpe militar, no Brasil, e pela instauração do regime totalitário. Nas décadas subsequentes, de 1970 a 80, houve mudanças políticas significativas graças a movimentos sociais de reivindicação pela redemocratização e eleições diretas $^{(4)}$. Essa constatação histórica, talvez, possa explicar a desproporcionalidade entre os formados nos anos de 1980 e 1981, na EEUSP, considerando-se o fato de que a maioria dos egressos se formou no ano de 1981 (76,1\%), se comparado ao ano anterior $(23,9 \%)$, o que se deve, provavelmente, a movimentos estudantis de paralisação e reivindicação na Universidade nesse período.

O curso de graduação recebe anualmente cerca de 80 alunos selecionados por meio de um concurso vestibular, e tem por finalidade formar bacharéis em enfermagem e enfermeiros obstétricos, além de enfermeiros com licenciatura. A partir do ano de 2005, extinguiu-se a especialização em Enfermagem Obstétrica na EEUSP, dada a criação de um curso específico de Obstetrícia no campus da USP Leste.

A Escola de Enfermagem da USP tem como meta a geração de novos conhecimentos e sua aplicação nas práticas assistencial e gerencial do enfermeiro, contribuindo para um processo de educação permanente dos profissionais de enfermagem.

Sendo assim, os objetivos desta investigação foram: identificar o perfil dos egressos da Escola de Enfermagem da Universi-dade de São Paulo no período de 1980 a 1981 e contribuir para a recuperação da memória dessa instituição e sua inserção no conjunto das escolas de enfermagem consideradas pioneiras no Brasil.

\section{MÉTODOS}

A população foi constituída por 163 ex-alunos formados na Escola de Enfermagem da USP, no período de 1980 a 1981. Do universo pesquisado foram sorteados, de forma aleatória, $10 \%$ da população, que atenderam aos seguintes critérios de inclusão: terem se formado nessa Escola no período de 1980 a 1981 e após assinatura do Termo de Consentimento Livre e Esclarecido aceitaram participar de forma livre e espontânea do estudo proposto.

Foram coletados os dados sócio-demográficos dos exalunos formados na Escola de Enfermagem da USP, no período supracitado, utilizando-se dos registros arquivados no Serviço de Graduação da EEUSP. Em seguida, foram realizadas as entrevistas com os 16 colaboradores selecionados pela amostragem.

Utilizou-se instrumento para a coleta dados concernentes ao perfil sócio-demográfico do universo pesquisado, após a aprovação do Comitê de Ética em Pesquisa da Escola de Enfermagem da Universidade de São Paulo. Os resultados foram apresentados em forma de gráficos e tabela e discutidos com base nos levantamentos bibliográficos acerca da temática.

\section{RESULTADOS}

O número absoluto da população estudada foi de 163 exalunos, sendo que destes, 23,9\% se formaram em 1980 e 76,1\% em 1981. A população é caracterizada por ser predominantemente feminina $(98,7 \%)$. Constatou-se que 58,9\% dos ex- 


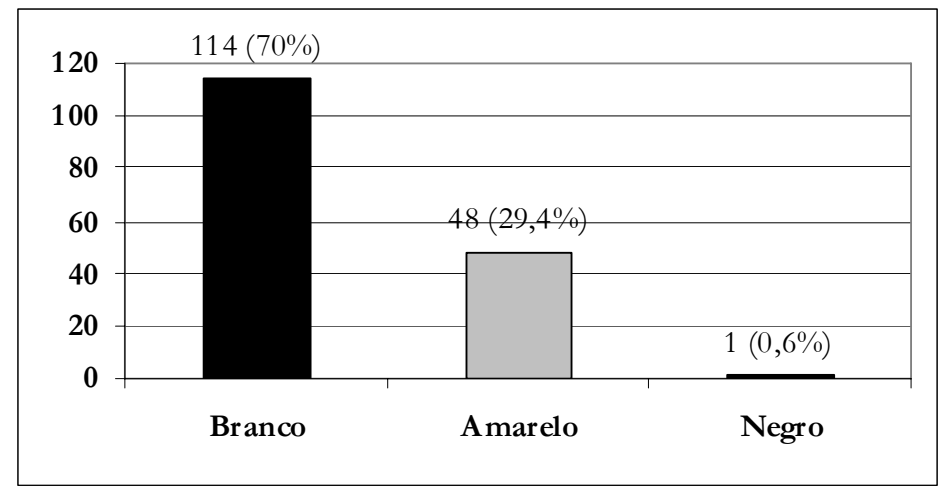

Figura 1. Cor/etnia dos ex-alunos da EEUSP participantes do estudo, 1980-1981. São Paulo, 2007.

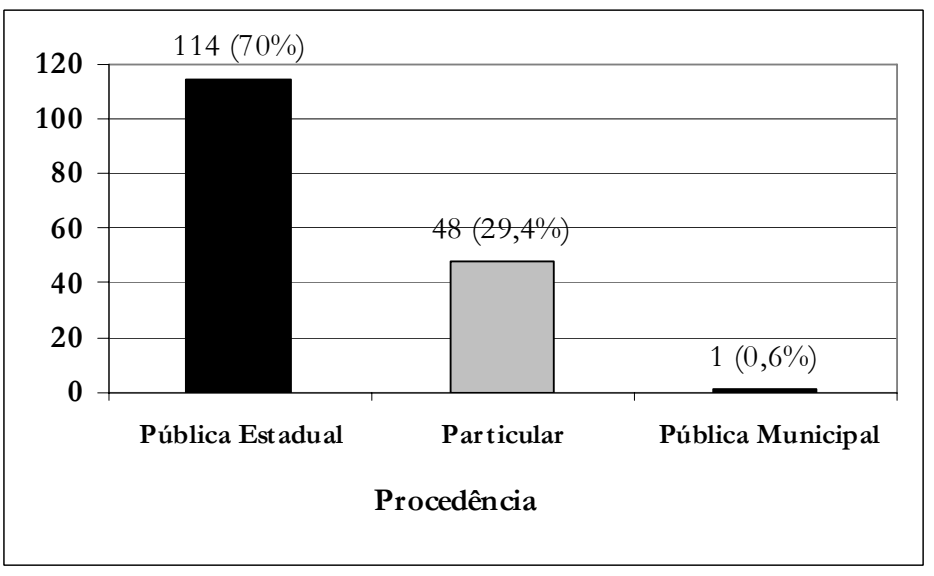

Figura 2. Tipo de instituição cursada no ensino médio dos exalunos da EEUSP participantes do estudo, 1980-1981. São Paulo, 2007.

Tabela 1. Ano de nascimento dos ex-alunos da EEUSP participantes do estudo, 1980-1981. São Paulo, 2007.

\begin{tabular}{ccc}
\hline Ano de Nascimento & $\mathbf{n}$ & $\mathbf{\%}$ \\
\hline 1950 & 1 & 0,6 \\
1952 & 1 & 0,6 \\
1953 & 2 & 1,2 \\
1954 & 9 & 5,5 \\
1955 & 8 & 4,9 \\
1956 & 20 & 12,2 \\
1957 & 36 & 22,0 \\
1958 & 45 & 27,6 \\
1959 & 26 & 15,9 \\
1960 & 6 & 3,6 \\
1961 & 1 & 0,6 \\
\hline Tot al & $\mathbf{1 5 5}$ & $\mathbf{1 0 0 , 0}$ \\
\hline
\end{tabular}

Do total de ex-alunos estrangeiros, $1,9 \%$ eram procedentes da China, $1,2 \%$ de Portugal, $0,6 \%$ de Taiwan, 0,6\% do Peru e 0,6\% do Egito. Essa quantidade de alunos estrangeiros existente nos cursos de graduação em enfermagem na EEUSP pode ser devido ao grande afluxo de imigrantes para o nosso país, a partir das décadas de 1920 e 1930.

Em relação à côr/etnia, a Figura 1 demonstra que $70 \%$ dos ex-alunos da EEUSP, no período estudado, eram brancos; 29,4\% amarelos e 0,6\% negros.

Quanto às instituições de ensino médio em que esses ex-alunos se formaram, podemos constatar que $114(70 \%)$ estudaram em escolas públicas estaduais; $48(29,4 \%)$, realizaram seus estudos em escolas privadas e apenas $1(0,6 \%)$ frequentou escola pública municipal (Figura 2).

Os dados desta investigação revelaram, ainda, em seu conjunto, que os pais dos ex-alunos da EEUSP, no período estudado, não possuíam ensino superior e as mães dedicavam-se às atividades domésticas.

A maior parte dos ex-alunos ingressou entre o período de 1976 a 1978, sendo que destes, 21,5\% ingressaram em 1976; 35\% em 1977 e 35,6\% em 1978.

A Tabela 1 apresenta o perfil destes ex-alunos quanto ao ano de nascimento. A maioria dos exalunos nasceu na década de 1950, sendo que destes $17,2 \%$ nasceram em 1956; 22,1\%, em 1957; 27,6\%, em 1958 e 16\%, em 1959. Os dados, ao serem interpretados na perspectiva do tempo de duração do curso de enfermagem na EEUSP, (que já durava quatro anos), demonstra que os alunos ingressaram na universidade com idade média de dezenove anos.

Em relação à opção pelo curso de enfermagem, os dados seguintes possibilitam a melhor compreensão do contingente daqueles ex-alunos que optaram por esta carreira como primeira ou segunda escolha. Constatou-se que a maioria, ou seja, 87,5\% dos entrevistados optaram pela enfermagem como primeira opção, e que, $12,5 \%$ escolheram essa carreira como segunda opção (Figura 3).

A Figura 4 mostra que $20,0 \%$ dos sujeitos investigados participaram de atividades do Centro Acadêmico da própria Escola; 10\% desenvolviam projetos de iniciação científica com acompanhamento docente; $15 \%$ frequentavam atividades ligadas a entidades de classe (Associação Brasileira de Enfermagem ou sociedades de especialistas de enfermagem) e 10\% eram participantes de ligas alunos eram procedentes de São Paulo, capital; 27\%, de outras cidades do Estado de São Paulo; 9,2\%, de outros Estados do Brasil e 4,9\%, de outros países. Estes dados demonstram que houve grande procura pela EEUSP por parte daqueles que não residiam na capital, embora não tenhamos elementos para a discussão acerca dessa constatação. estudantis. Cabe ressaltar que um quarto $(25,0 \%)$ dos sujeitos investigados desenvolvia outras atividades na enfermagem, como monitorias de disciplinas, sob a supervisão docente, junto à própria escola. Entretanto, 20,0\% dos ex-estudantes daquele período referiram que não participavam de qualquer tipo de atividade extra curricular. 


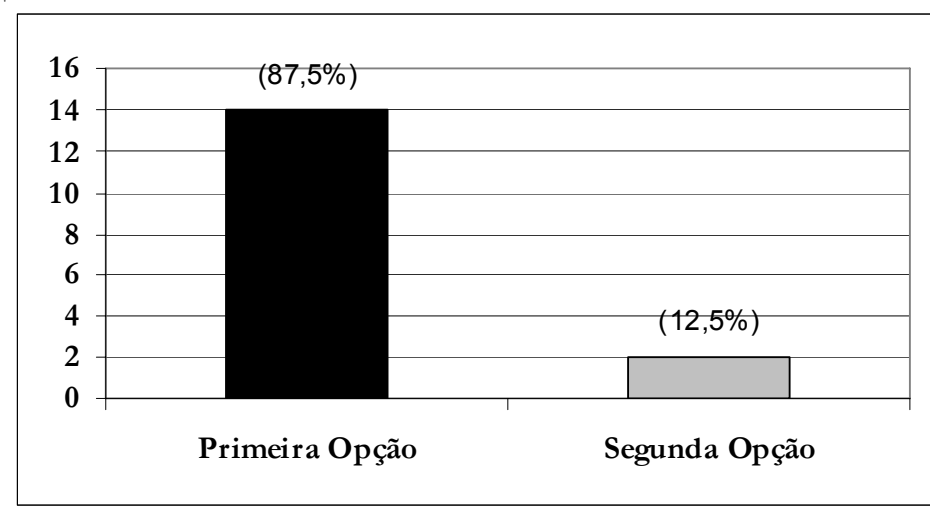

Figura 3. Opção pela enfermagem da mostra dos ex-alunos da EEUSP participantes do estudo, 1980-1981. São Paulo, 2007.

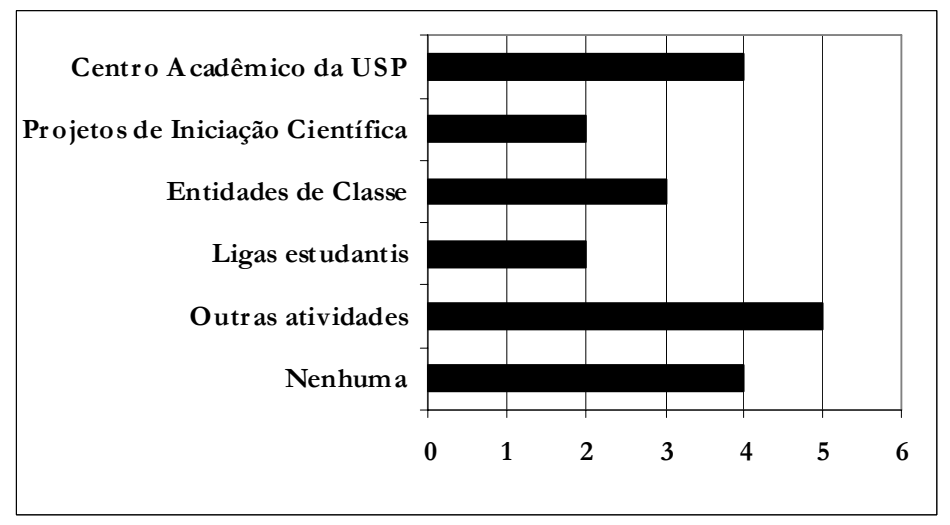

Figura4. Ex-alunos da EEUSP form ados no período de 19801981, segundo a participação em atividades acadêmicas. São Paulo, 2007.

\section{DISCUSSÃO}

De 1942 a 1991, a Escola de Enfermagem da USP diplomou 1.890 bacharéis em Enfermagem; 701 enfermeiros com habilitações em Enfermagem e 308 terminaram cursos de especialização. De 1959 a 1970, essa mesma Escola ofereceu cursos de pós-graduação lato sensu em Pedagogia e Didática aplicada à Enfermagem e de Administração de Serviço de Enfermagem por onde passaram 491 enfermeiros, sendo 431 brasileiros e 60 estrangeiros.

Do total dos ex-alunos participantes deste estudo, 23,9\% se formaram em 1980 e 76,1\% em 1981. A causa dessa desproporcionalidade de formandos entre um ano e outro não representou o interesse de investigação direto, porém há relatos de que movimento reivindicatório grevista na Universidade de São Paulo, naqueles anos, poderá ter influenciado na postergação da conclusão do curso para aqueles alunos formados nos anos de 1980 e 1981.

Apenas 1,2\% eram do sexo masculino, isso se deve ao fato da enfermagem ser uma profissão predominan-temente feminina. Esse achado vem corroborar o movimento de feminilização da profissão a partir do advento da
Enfermagem Moderna, final do século XIX, na Europa, e início do século XX em outros países do mundo, como Estados Unidos e Brasil. Nesse período, observa-se que o movimento de profissionalização da enfermagem possibilitou a criação de uma ocupação útil e adequada às mulheres que buscavam trabalho fora do círculo doméstico. Dessa forma, Florence Nightingale (fundadora da moderna educação de enfermagem profissional, na Inglaterra) contribuiu para elevar o status social da profissão da enfermagem e garantir uma ocupação digna para a mulher ${ }^{(5)}$.

É sabido, entretanto, que bem antes de Florence Nightingale, durante a Idade Média, a presença dos religiosos nas práticas do cuidado era muito expressiva, sobretudo das ordens e congregações masculinas voltadas para as atividades de enfermagem, destacando-se, nesse contexto, a Ordem dos Enfermeiros Hospitalários de São João de Deus, em Granada, Espanha, bem como a Ordem dos Ministros dos Enfermos, na Itália, ambas surgidas no contexto do século XVI. Essas ordens tinham um corpo de enfermagem composto por homens, que se dedicavam por meio de votos à prática da enfermagem, que possuía um caráter caritativo, de bondade e abnegação no serviço aos doentes, pobres e desabrigados ${ }^{(5-6)}$.

O homem aparece, então, na enfermagem, em decorrência da grande influência das ordens religiosas e militares, pela necessidade da força física nas áreas da psiquiatria e ortopedia ou por outro motivo como a separação dos pacientes em enfermarias conforme o sexo, ou seja, era necessária a presença masculina na enfermagem para atender a urologia. Desse modo, percebe-se a importância do aspecto cultural na assistência, separando-se os doentes por sexo, o que poderá ter influenciado na manutenção da figura do homem na enfermagem para tratar dos doentes do mesmo $\operatorname{sexO}^{(7)}$.

No que concerne à questão cor/etnia, a história da enfermagem brasileira, desde seus primórdios, evidencia embates provocados por tentativas de ingresso de mulheres negras em escolas de enfermagem. Um desses episódios originais, vividos por dirigentes e alunas da Escola de Enfermeiras do Departamento Nacional de Saúde Pública (atualmente Escola de Enfermagem Anna Nery), Rio de Janeiro, fundada em 1923, ressaltou o problema gerado pela segregação racial nas origens da formação da identidade profissional da enfermagem brasileira, sendo bastante esclarecedor:

"É verdade que a política de organização da escola tinha sido evitar (diplomática e estrategicamente) a admissão de negros, justificando-se essa situação. Isto era fundamental se se pretendia atrair mulheres de melhor classe social. Mesmo a Academia Naval, colocava obstáculos para impedir a admissão de candidatos negros. Todas as vezes em que as moças de cor se candidatavam para entrar na escola, havia sempre outras boas razões para que elas não fossem 
qualificadas, por isso nenhum problema havia surgido até então. Na verdade, havia já na escola três estudantes que, apesar de brancas, mostravam alguns traços de sangue negro. Foi enviada uma carta à impressa comunicando que nenhuma pretendente havia sido rejeitada por causa da cor, mas não foi convincente, e o Departamento de Saúde achou que seria aconselhável permitir o ingresso de uma moça negra, se acaso se apresentasse alguma que preenchesse todos os requisitos para a admissão. Esta candidata apareceu em março (1926), juntamente com as demais pretendentes sob forte suspeita de que havia sido mandada por um dos jornais, e foi admitida. Isto provocou uma enxurrada de queixas por parte das alunas, mas após considerar a questão, o Conselho de Estudantes finalmente decidiu que qualquer manifestação de rejeição ou de descortesia para com uma colega de classe demonstraria falta de respeito e de vontade de cooperar, e assim não houve mais dificuldades. As estudantes deixaram claro, contudo, que esperavam que não fosse admitida nenhuma outra moça negra por algum tempo"(5).

Em relação a escolha, frequentemente, a profissão de Enfermagem é buscada por aqueles que, pelos motivos mais variados, se identificam com a área da saúde ${ }^{(6)}$. Estudos realizados por outros autores revelam que os alunos ingressam no curso de enfermagem, geralmente, com sentimentos ambivalentes, tais como: realização pessoal, insegurança, desejo de vitória, valorização, esperança, medo e solidão, decorrentes dos momentos de vida que estão vivenciando. Por outro lado, a superação do concurso vestibular, que é, normalmente, percebido como um momento difícil, o primeiro contato com a universidade, bem como o desconhecimento do conteúdo a ser ministrado no curso escolhido e a incerteza do futuro são alguns fatores importantes e que podem justificar os sentimentos mencionados ${ }^{(8)}$.

A escolha da profissão de Enfermagem pelos alunos que realizaram vestibular para essa carreira (na Escola de Enfermagem Anna Nery da Universidade Federal do Rio de Janeiro) baseou-se, principalmente, na inclinação para a área da saúde. Assim, os alunos de enfermagem, muitas vezes, optam por esta carreira porque o sistema de seleção universitária ainda reproduz as diferenças existentes entre

\section{REFERÊNCIAS}

1. Sauthier J, Carvalho V. A Missão Parsons: documentos históricos da EEAN/UFRJ - 1922-1931. Rio de Janeiro: Anna Nery; 1999

2. Sauthier J. As enfermeiras norte-americanas e o ensino da enfermagem na capital do Brasil: 1921-1931. Rio de Janeiro: Escola de Enfermagem Anna Nery; 1999.

3. Carvalho AC. Resumo histórico: 1942-1980. Rev Esc Enferm USP, 1980; 14 (Supl.):1-271 .

4. Fausto B. História do Brasil. 8a ed. São Paulo: Edusp; 2000 .

5. Oguisso T, organizador. Trajetória histórica e legal da enfermagem. Barueri: Manole; 2007.

6. Siles J. Historia de la enfermería española. Alicante: as classes sociais e que reflete nas carreiras de menor "status" social, na qual predominam alunos procedentes das classes de menor poder aquisitivo e cultural $^{(9)}$.

Os resultados contribuem para o resgate da "memória coletiva", por ser esta, além de uma conquista, um instrumento e objeto de poder ${ }^{(10)}$. Sendo assim, os achados desta investigação asseguram maior visibilidade acerca da trajetória histórica da EEUSP, revelando a identidade social dessa instituição, por meio do perfil e da história de ex-alunos nela formados.

\section{CONCLUSÕES}

A maioria dos ex-alunos da EEUSP detinha o perfil social de serem mulheres (tendo apenas dois homens); solteiras; nascidas entre 1956 a 1959; paulistanas; brancas que cursaram o ensino médio em escolas públicas e escolheram a enfermagem como primeira opção.

Como podemos constatar, os dados quantitativos respondem aos objetivos da presente investigação no que tange ao perfil e à identificação dos sujeitos investigados. Nessa direção, parece-nos claro que os estudos históricos da enfermagem propiciam melhor compreensão da trajetória, memória, identidade da profissão e das representações que são construídas socialmente e atribuídas à enfermeira.

Os achados da presente investigação possibilitaram compreender melhor o perfil dos ex-alunos egressos da Escola de Enfermagem da USP, no período delimitado temporalmente, e revelaram a relevância de estudos acerca da identidade profissional, enquanto um fator decisivo para a discussão acerca da construção, desconstrução e reconstrução do passado, em projeção para o presente e o futuro do enfermeiro; revelando, ademais, a necessidade social de preservação da memória profissional ou coletiva ${ }^{(1)}$. Desse modo, os achados desta investigação contribuirão para resgatar a memória da história da Escola de Enfermagem da Universidade de São Paulo, ampliando o conhecimento sobre o perfil dos egressos dessa instituição e resgatando a questão da escolha profissional, pois ao lançar-se novo olhar sobre o passado, torna-se possível conhecer melhor o futuro da profissão.
Aguaclara; 1999.

7. Pereira A. Reflexões sobre a evolução da enfermagem e o surgimento do homem na profissão. Acta Paul Enferm. 1991;4(2/4): 49-54.

8. Spindola T, Moreira A. O aluno e a enfermagem: por que esta opção profissional? Esc Anna Nery Rev Enferm. 1999;3(3):25-36.

9. Menezes SS, Baptista SS, Barreira IA. O perfil das(os) alunas(os) de enfermagem da Escola de Enfermagem Anna Nery: décadas de 20, 30 e 90. Esc Anna Nery Rev Enferm. 1998;2(1/2):34-48.

10. Barreira IA. Memória e história para uma nova visão da enfermagem no Brasil. Rev Latino-am Enfermagem. 1999; 7(3):87-93. 